\title{
New Challenge to Optimize Wells Drilling Using the Geomechanical Model Design
}

\author{
Kenny Escobar-Segovia ${ }^{1,2}$, Romel Erazo-Bone ${ }^{1,3}$, Carlos Portilla-Lazo ${ }^{3}$, Danilo Arcentales-Bastidas ${ }^{1}$, Fidel \\ Chuchuca-Aguilar ${ }^{3}$, Dario Cedeño-Macias ${ }^{3}$, Alexander Herrera-Mendoza ${ }^{1}$, and Edison Uguña-Guachilema ${ }^{1}$. \\ ${ }^{1}$ Escuela Superior Politécnica del Litoral, ESPOL, Facultad de Ingeniería en Ciencias de la Tierra, Campus Gustavo Galindo Km \\ 30,5 Vía Perimetral, P.O. Box 09-01-5863, Guayaquil, Ecuador, kescobar@espol.edu.ec, raerazo@espol.edu.ec, \\ daanarce@espol.edu.ec, alraherr@espol.edu.ec, juguna@espol.edu.ec \\ ${ }^{2}$ Universidad Espíritu Santo - Ecuador, kescobarsegovia@gmail.com \\ ${ }_{3}^{3}$ Universidad Estatal Península de Santa Elena, Ecuador, raerazo@upse.edu.ec, fchuchuca@upse.edu.ec, cportilla@upse.edu.ec, \\ dcedeño@upse.edu.ec
}

\begin{abstract}
The objective of this project is to develop a geomechanical model based on porosity oil well logging from selected wells in ESPOL (Escuela Superior Politécnica del Litoral) field and to study the stability of the wells in Block 57 of the North Oriente Basin, in order to optimize future drilling in the Paleogene in the intervals of the Oligocene and Eocene with the aid of an optimum operational drilling window, focused on the TIYUYACU formation due to the high content of arcillosity it presents. The methodology of this project is based on: 1) Information selection, 2) Geological analysis, 3) Estimation of pore pressures, fracture and main well stresses, 4) Estimation of the mechanical properties of the formation, 5) Fault analysis with the Mohr Coulomb criterion, 6) Determination of the optimal operational window. This information will be useful for calibrating and optimizing the operational window for drilling muds, for future vertical and directional wells, both in the field of study and in neighboring oil fields
\end{abstract}

Keywords-- Geomechanical Model, Geopressures, Instability, Mud Window, Electrical Logs.

\section{INTRODUCTION}

A well, it is considered stable when the diameter of the well is equal to that of the bit with which it is being drilled. Hence, instability of the well was described as the mechanical conditions that cause faults through compression or stress within the well [1].

During a well drilling, a distortion of the field of stress occurs, which is redistributed around the hole, causing well instability and inducing shear stress and sometimes causing faults, as these stresses can exceed the strength of the rock. In addition, formation faults may occur due to other stress effects, especially when the hydrostatic pressure of the well is greater or less than the formation pressure. In the Oriente basin most of the hole instability problems occur in the TIYUYACU formation, which is why this study focuses on the mechanical problems of said formation.

A Geomechanical Model allows establishing the behavior of the rock along the entire perforated stratigraphic sequence, which helps the geomechanical characterization of the sector. The final results show the magnitude of in-situ stresses,

Digital Object Identifier (DOI): http://dx.doi.org/10.18687/LACCEI2018.1.1.447 ISBN: 978-0-9993443-1-6

ISSN: 2414-6390 drilling muds optimum operational windows, an assessment of pore pressure and fracture, collapse pressure based on some criterion of failure and mechanical properties of the rock [2].

The developed Geomechanical Model was based on information obtained from porosity oil well logging acquired in two wells in the ESPOL field. The information provided focuses on the TIYUYACU formation, due to its high content of clay that causes the greatest problems of instability in the well during drilling operations.

\section{LOCATION}

The ESPOL field with an extension of $177.4 \mathrm{~km} 2$ is located in block 57 which has an extension of $1540 \mathrm{~km} 2$, corresponding to the north zone of the Oriente Basin approximately $12 \mathrm{~km}$ to the east of the Lago Agrio field in the province of Sucumbíos. Its Geographic coordinates are showing below [3]:

Longitude: 76 $76^{\circ} 52^{\prime \prime} \mathrm{W} \quad 76^{\circ} 47^{\prime} 25^{\prime \prime} \mathrm{W}$

Latitude: $\quad 00^{\circ} 04^{\prime} 28^{\prime \prime} \mathrm{N} \quad 00^{\circ} 02{ }^{\prime} 25^{\prime \prime} \mathrm{S}$

The field limits are:

To Northeast by the Lago Agrio field.

To Northwest by the Parahuaco and Atacapí fields.

To Southeast by the Shushufindi field.

To Southwest by the Sacha field.

\section{GEOLOGICAL FRAMEWORK}

The ESPOL field is an elongated anticlinal structure with a $\mathrm{N}-\mathrm{SW}$ direction, $16 \mathrm{~km}$ long by $4.5 \mathrm{~km}$ wide. To the east it is limited by a sliding fault and its lower limit of main reservoir $\mathrm{T}$ is controlled by an L.K.O. of 8779 '. The structural configuration of the field it is determined by reverse and sliding faults, as shown in Figure 1.

This project will focus on the TIYUYACU Formation of the Oriente Basin, due to its great instability and complexity at the time of drilling. The lithology of the TIYUYACU Formation is constituted of red brown arcillolites in 78\%, interspersed with sandstones in $1 \%$ and limolites in $1 \%$, also of a superior conglomerate body constituted of quartz in $20 \%$. The instability of the formation of interest is due to the high

$16^{\text {th }}$ LACCEI International Multi-Conference for Engineering, Education, and Technology: "Innovation in Education and Inclusion", 19-21 July 2018, Lima, Peru. 
composition of clay and for this reason, it is vital for the geomechanical study in this area to elaborate a mud optimum operational window to reduce costs or NPT (Non Productive Time).

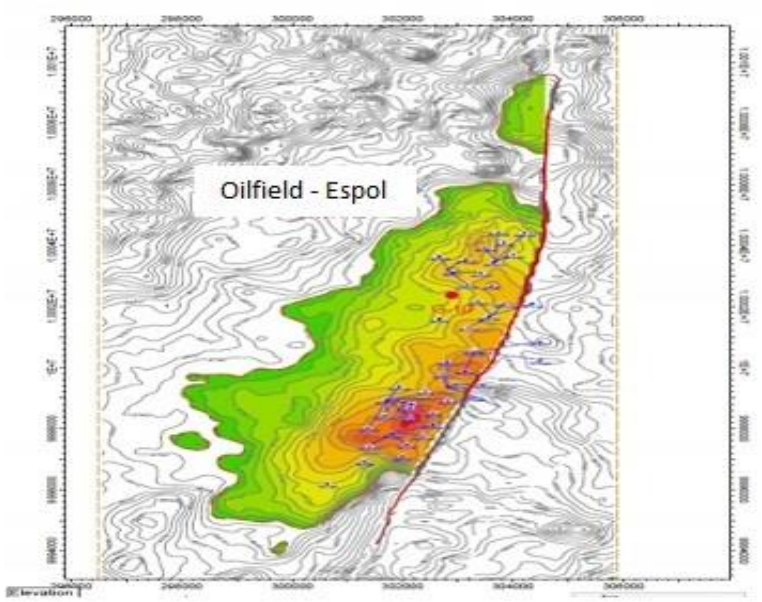

Fig.1, ESPOL field location. Source: Petroamazonas EP, 2017 [4].

\section{GEOMECHANICAL MODEL}

The following Geomechanical model is constructed based on porosity oil well logging from the selected wells (FICT001 and FICT002), basing the construction of the mud operational window on the in-situ stresses and pore pressure acting on the well, obtaining the interval of operation during drilling, taking into account collapse and fracture pressures [5].

The flowchart of the construction of the Geomechanical Model in the Interactive Petrophysics software is showing in Figure 2.

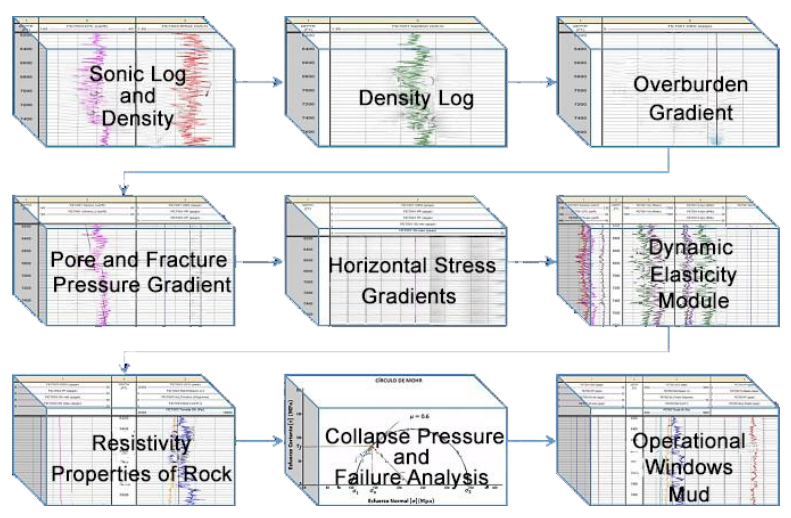

Fig. 2,ESPOL field location. Source: Herrera, et. al. 2017.

\section{DENSITY WELL LOGGING FROM GARDNER METHOD}

The Gardner equation (1974) calculates the Bulk Density of the formation, based on the information of transit time in different intervals, this information is provided by the sonic well $\log$.

To do this, the Interactive Petrophysics program will be used, in which data will be identified where the. LAS file indicates missing values (-999), which will be the zone will be completed by the Gardner equation, presented below [6]:

$\mathrm{RHOB}=c\left((10)^{\wedge} 6 / \Delta t\right)^{\wedge} e$

Nomenclature:

$\mathrm{c}=$ Gardner Constant

$\Delta t=$ Transit Time

$e=$ Euler

\section{OVERLOAD GRADIENT}

The vertical stress is caused due to the weight of the sediments that have been deposited in the basin. The vertical stress depends on the thickness and density of the formations, which will be calculated using the Zamora method, which depends on the geological age of the rock [7].

Because the Tiyuyacu formation which is the zone of interest belongs to a geologic age between the Oligocene and the Eocene, the equation to calculate the overload gradient is as follows:

$O B G=\sigma_{v} / D=1 / D\left[(8.030+0.232(9)) D^{\wedge} 1.075\right]$

Nomenclature:

OBG = Overburden Gradient

$\sigma_{v} \quad=$ Vertical Stress

$D \quad=$ Depth

\section{PORE AND FRACTURE PRESSURE GRADIENT}

Pore Pressure Gradient.-The Eaton method (1975) will be used, which establishes a difference between the transit time obtained with the sonic log and an estimate of the normal compacting tendency to deduce the increase in the pore pressure[8].

In the analysis carried out in the present study, the compaction train was used according to its established linear tendency. The calculations were made with the help of the "Interactive Petrophysics" program.

$P P=O B G-\left(O B G-P P_{n}\right)\left(\Delta t_{n} / \Delta t\right)^{\wedge} 3$

Nomenclature:

$\mathrm{PP}=$ Pore Pressure

$P P_{n}=$ Normal Pore Pressure

$\Delta t_{n}=$ Normal Transit Time

Fracture Pressure Gradient.- It is important to be aware of the fracture gradient in weak zones to avoid fracture problems and mud flowing into the formation, the fracture pressure is known as the pressure at which a rock begins to lose cohesion between its grains.

The Eaton method (1969) assumes that the land formations present elastic properties, relating the effective horizontal stress $\sigma_{\mathrm{h}}{ }^{\prime}$, and the effective vertical stress $\sigma_{v}{ }^{\prime}$, w through the Poisson relation, its equation is presented below [9]:

16 $^{\text {th }}$ LACCEI International Multi-Conference for Engineering, Education, and Technology: "Innovation in Education and Inclusion", 19-21 July 2018, Lima, Peru. 
$P F=P P+(v /(1-v))(\mathrm{OBG}-P P)$

(4).

Nomenclature:

$\mathrm{PF}=$ Fracture Pressure

$v=$ Poisson relation

The Poisson relation $(v)$ is a mechanical property of the formation that relates the lateral deformation of the rock with its axial deformation, when it is subjected to a stress, in the present project such will be obtained by means of Eaton's nomogram, which is a function of the depth of each formation of interest, as shown below:

$v=0.0645 * \ln (D)-0.0673$

\section{HORIZONTAL STRESS}

Minimum Horizontal Stress.- In drilling, it is necessary for the mud weight to be kept below the minimum horizontal stress $\left(\mathrm{Sh}_{\min }\right)$ so as to avoid accidental hydraulic fracturing and loss of circulation problems. It is must also be maintained above the forming pore pressure to avoid problems such as a pressure kick (Kick) and above the minimum weight of mud required to prevent well failures [10].

The method used for the calculation of the minimum horizontal stress is given only for land wells and with depths less than 11500 feet considering the formation of interest, also it relates the pore pressure, normal pore pressure and depth, as presented in the following equation expressed in psi:

$\sigma_{h}=0.197 D^{\wedge} 1.145+0.46\left(P P-P P_{n}\right)$

Nomenclature:

$\sigma_{h}=$ Horizontal Stress

Maximum Horizontal Stress.-Due to the fact that no cores were obtained from the formation, it is impossible to know the data on the deformation caused by this stress, and in the absence of measurements of some hydraulic fracturing that directly provides the value of the horizontal maximum stress, Geomechanics studies were performed near the area of interest.

Therefore, with the help of studies carried out in the area of Geomechanics in the ESPOL oil field, it was possible to define the existence of a transcurrent stress regime (strike slip) with a coefficient of friction equal to 0.6 , which allowed to determine the following equation that relates the maximum and minimum horizontal stresses with the pore pressure and the coefficient of friction $(\mu)$ :

$\sigma_{H}=0.6\left(S_{\min }-P P\right)+P P$

IX. DYNAMIC MODUluS OF ELASTICITY
For the construction of the Geomechanical Model it is necessary to define the elastic properties of the TIYUYACU formation. The characteristics of resistance and deformation of the rocks must be known to carry out analysis of their behavior under the conditions of wellbore drilling [11].

Elastic properties of Shear Modulus $\left(\mathrm{G}_{\mathrm{dyn}}\right)$, Volumetric Modulus $\left(\mathrm{K}_{\mathrm{dyn}}\right)$, Young Modulus ( $\left.\mathrm{E}_{\mathrm{dyn}}\right)$, and Poisson Ratio $(v)$ are calculated for each depth. These calculations are performed with equations based on the theory of propagation of sound waves and empirical correlations from the sonic logs. The source of information used in the model is the sonic log, which allows us to obtain the curves of the transit time of the compression wave, together with the density values recorded in the same stratigraphic interval.

This information, along with the sonic well log, are the basic log measurements that allows the determination of the dynamic elastic properties for each formations of the ESPOL oil field using the selected wells log (dipole sonic Image). Which is the time curve of the compressional wave was used to find it through an empirical correlation for formations with high clay content. The equations for calculating the cut wave velocity are presented below, and the Elasticity:

$\mathrm{V}_{\mathrm{S}}=0.842 \mathrm{~V}_{\mathrm{P}}-1.099$

$G_{d y n}=13474.45\left(R H O B / \Delta t_{s}\right)$

$K_{d y n}=13474.45\left(R H O B /\left(\Delta t_{c}\right)^{\wedge} 2\right)-(4 / 3) G_{d y n}$

$E_{d y n}=\left(9 G_{d y n} * K_{d y n}\right) /\left(3 K_{d y n}+G_{d y n}\right)$

Nomenclature:

$\mathrm{V}_{\mathrm{p}} \quad$ = Primary Wave Velocity.

$\mathrm{V}_{\mathrm{s}}$ = Second wave Velocity.

$\mathrm{G}_{\text {dyn }}=$ Shear Modulus.

$\mathrm{K}_{\text {dyn }}=$ Volumetric Modulus.

$\mathrm{E}_{\mathrm{dyn}}=$ Young Modulus.

$\Delta t_{c}=$ Transit Time.

\section{ROCK RESISTANCE PROPERTIES}

The strength of a rock sample is commonly measured in tension or compression. In a Geomechanical Model the resistance properties of the most used rocks are [12]:

- Uniaxial Compressibility Resistance

- Tension Resistance.

Because the study wells in the present project do not have laboratory tests information for us to find the rock resistance properties, it was necessary to use correlations based on electrical logs obtained from the wells.

\section{UNIAXIAL COMPRESSIBILITY RESISTANCE}

Most of the methods relate UCS to P-wave velocity and porosity. For the present study, we will use the relation for formations with high clay content, its equation is presented below [13]:

$U C S=108.75\left[304.8 / \Delta t_{c}\right]^{\wedge} 2.93$

(13).

16 $^{\text {th }}$ LACCEI International Multi-Conference for Engineering, Education, and Technology: "Innovation in Education and Inclusion", 19-21 July 2018, Lima, Peru. 
Nomenclature:

UCS $=$ Resistencia de la Compresibilidad Uniaxial.

Tensile Resistance.- The tensile strength in the present project will be calculated using the equation, given by the following expression:

$\mathrm{T}_{\mathrm{o}}=0.1 * \mathrm{UCS}$

Nomenclature:

$\mathrm{T}_{0}=$ Resistance to stress

Internal Friction Angle.-The internal friction angle, $\varphi$, is related to the coefficient of internal friction. It has an allowable variation of $0^{\circ}$ to $90^{\circ}$ (in practice this value is approximately $30^{\circ}$ ). In this project, we will calculate this value with an equation that relates the internal friction angle with the compressive transit time:

$\varphi=\arcsin \left[\left(\left(304.8 / \Delta t_{c}\right)-1\right) /\left(\left(304.8 / \Delta t_{c}\right)+1\right)\right]^{*} 180 / \pi$

Nomenclature:

$\varphi=$ Internal Friction Angle.

Biot Coefficient.- This coefficient presents the relationship between the consistency of a multi-porous rock and the consistency of the matrix. Its equation relates the Biot coefficient with the Young modulus and the volumetric modulus of the matrix, as presented below:

$\alpha=1-\left[E /\left(7(1-2 v) x K_{m a}\right)\right]$

(16).

Nomenclature:

$\alpha=$ Biot Coefficient

$E=$ Young Modulus

\section{Collapse PRESSURE}

At a certain depth, the formations are exposed to a vertical stress $\sigma_{\mathrm{v}}$, a horizontal stress $\left(\sigma_{H}\right.$ y $\left.\sigma_{\mathrm{h}}\right)$ and pore pressure $\left(\mathrm{P}_{\mathrm{P}}\right)$. When drilling operations are performed on a well, the rock that surrounds the well will support the load that was previously supported by the removed rock. The rock can present two behaviors, if it is linear elastic, a concentration of stresses will be formed around the well [14].

If their behavior is weak, the concentration of stresses would cause a fault in the hole. This fault can be attenuated by correctly selecting the weight of the drilling mud. It is for this reason that it is necessary to calculate the collapse pressure by evaluating the acting stresses around the well (axial $\sigma_{\mathrm{Z}}$, radial $\sigma_{\mathrm{r}}$ and tangential $\sigma_{\theta}$ ) and how the in-situ stresses affect these.

Once the stresses around the hole have been determined, it is important to compare them with the resistance of the formation through a fault criterion. If the variation of stresses exceeds at some point the criterion of rock failure, the rock will fail. This problem is commonly known as "well failure".
Therefore, the well failure criterion refers to the boundary conditions for well failures to occur.

Mohr Coulmb Fault Criterion.- As to obtain the collapse pressure through the Mohr-Coulomb fault criterion we need to determine the stress regime in the hole wall and select its corresponding equation, in this case the regime is given in the following order:

$$
\left(\sigma_{\theta}\right)^{\prime}{ }_{\max }>\sigma_{\mathrm{z}}{ }^{\prime}>\sigma_{\mathrm{r}}{ }^{\prime}
$$

Therefore, the equation used to calculate de collapse pressure is given by the following:

$\left.P_{w}<\left(3 \sigma_{H}-\sigma_{h}+P P\left(\left(\tan ^{\wedge} 2 \beta\right)-1\right)\right)-U C S\right) /\left(\left(\tan ^{\wedge} 2\right) \beta+1\right)$

$\beta=\left(\varphi+90^{\circ}\right) / 2$

Nomenclature:

$P_{w}=$ Collapse pressure.

Mohr's Circle.- The construction of the Mohr's circle allows us to graphically evaluate the shear force $\tau$, and the effective normal stress $\sigma_{\mathrm{n}}$, on the fault that is formed during the failure process in terms of the application of the effective main stresses, $\sigma_{1}$ and $\sigma_{\mathrm{z}}$ (Zoback, M., 2007) [15].

In triaxial stress tests, at effective confining pressure, compression failures are showingn when a fault develops. The angle at which the fault develops is described by $\beta$, which is the angle between the normal fault and the maximum compressive stress, $\sigma_{1}$. For the construction of Mohr's circle the following equations are used:

$\tau_{f}=0.5\left(\sigma_{1}-\sigma_{3}\right) \sin (2 \beta)$

Nomenclature:

$\tau_{f}=$ Triaxial stress tests

$\sigma_{1}=$ Maximum compressive stress

$\sigma_{3}=$ Minimum compressive stress

\section{MUd OPTIMUM OPERATIONAL WINDOW}

According to the definitions of geomechanics, the mud density operational window is the range of density values that could be used to safely perform drilling operations. The minimum value of this window corresponds to the density of the mud required to avoid a collapse of the formation in the wellbore, meaning the highest value between the pore pressure and collapse pressure and the maximum value corresponds to the required mud density to prevent hydraulic fracturing during drilling, this corresponds to the fracture gradient.

\section{RESUlTS}

Geomechanical Analysis For Well FICT001.- In the first lane of Figure 3 the corrected density of the TIYUYACU formation is shown obtained through the Gardner method, since the initial data of the electrical logs had aberrant values 
in certain zones. The average density of the formation, marking the trend of the curve is approximately $2.45 \mathrm{gr} / \mathrm{cc}$, which indicates that the lithology of the formation is mostly clay.

The third lane represents the compressional and shear wave velocities of the formation of interest, which has an average value of 13000 and $11000 \mathrm{ft} / \mathrm{sec}$ respectively; this facilitates the determination of the elastic modules of the formation presented in the fourth lane.

In the fifth lane, the Poisson ratio is shown, whose value is approximately 0.4 , which is an indicator that corroborates the lithology of the formation of interest.

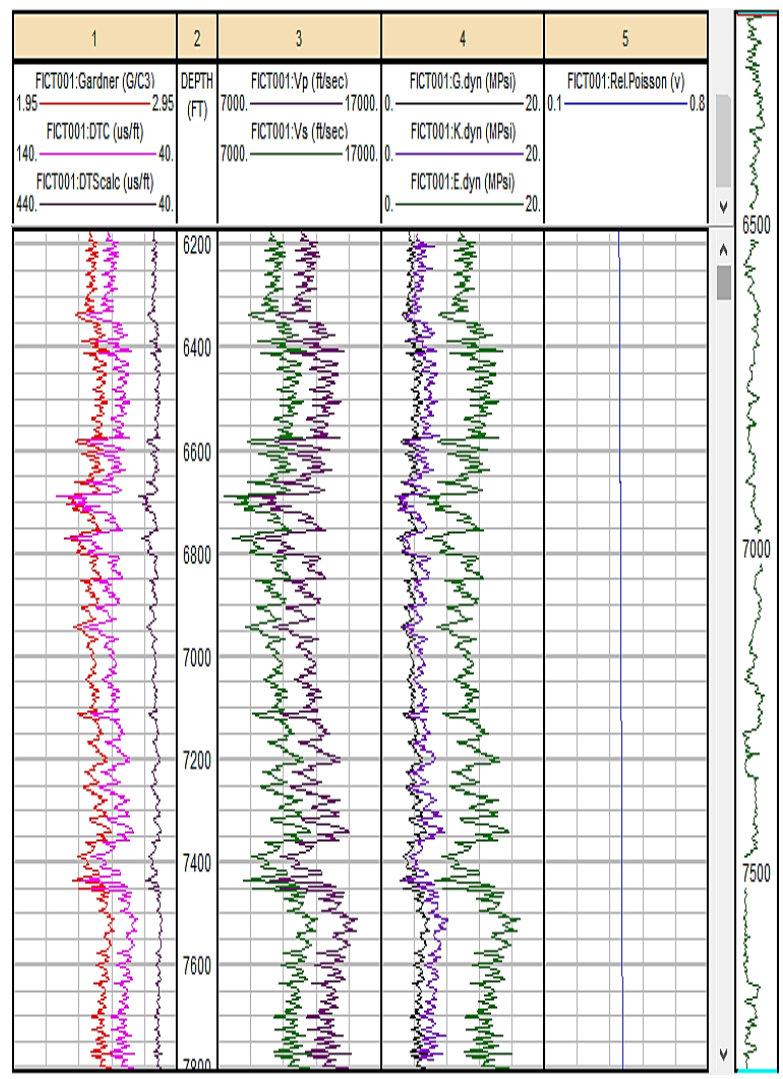

Fig.3, Tiyuyacu Formation Elastic Properties 6175' - 7808' (Well FICT001)

Source: Herrera, et. al, 2017.

The depth of the well (lane 1), the tendency of the main stresses (lane 2), the resistance properties of the rock (lane 3) and the mud operational window (lane 4) of well FICT001 are shown in Figure 4.

The third lane shows the properties of rock resistance, such as is the uniaxial compressibility resistance, which has values of about 5000 - 8000 Psia. The tensile strength that is approximately $10 \%$ of the value of the UCS, which serves as an indicator so that the weight of the drilling mud does not exceed this value causing a tensile failure resulting in hydraulic fracturing.
The Biot coefficient presents an average value of 0.85 , which is an indicator that the rock is an extremely plastic porous solid with a high pore pressure influence.
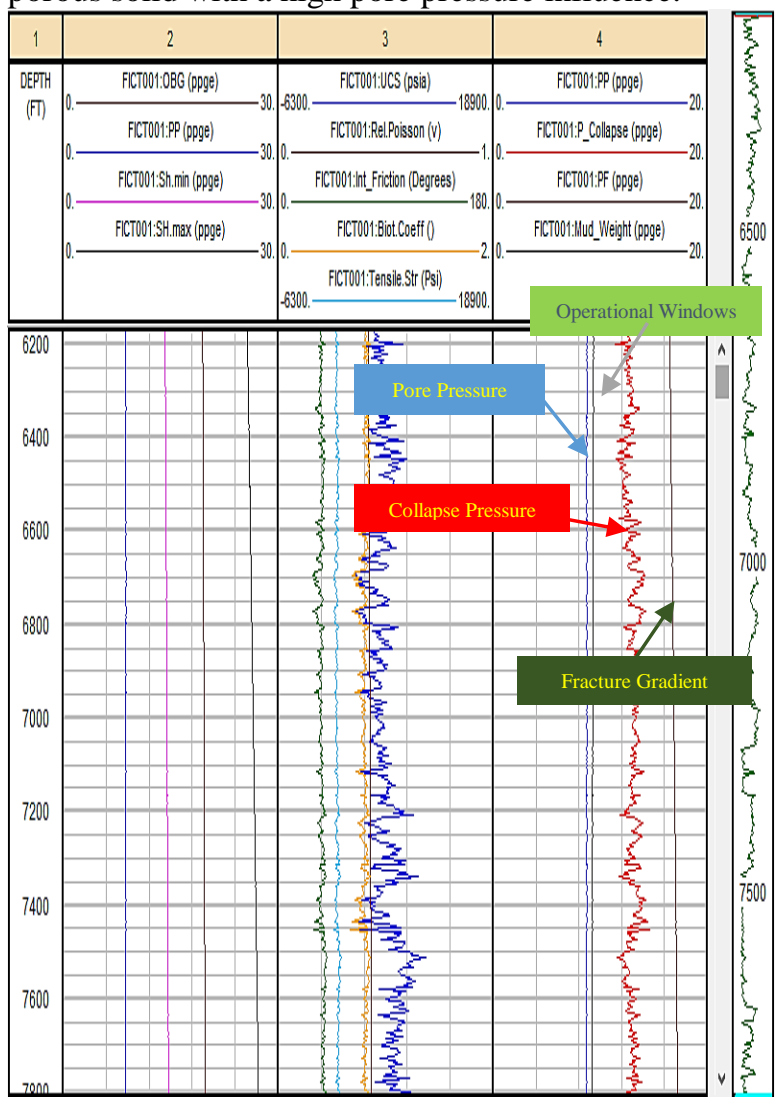

Fig. 4, Tiyuyacu Formation Mud Operational Window 6175' - 7808' (FICT001 well)

Source: Herrera, et. al. 2017..

The suggested mud weight values for well FICT001 are showing in table 1.

Table 1. Suggested Mud Weight for Drilling the Tiyuyacu Formation in Well FICT001.

\begin{tabular}{|c|c|}
\hline \multicolumn{2}{|c|}{ Suggested Mud Weight for Well FICT001 } \\
\hline $\begin{array}{c}\text { Approx. Depth } \\
\text { [ft TVD] }\end{array}$ & $\begin{array}{c}\text { Mud Weight } \\
\text { [ppge] }\end{array}$ \\
\hline $6175-7440$ & $13.7-15.1$ \\
\hline $7425-7808$ & $12.7-15.7$ \\
\hline
\end{tabular}

Source: Herrera, et. al. 2017.

Geomechanical Analysis for well FICT003.- In the first lane of Figure 5 the density log is shown, which did not have to be corrected, since it was complete for the TIYUYACU formation. The average density of the formation, marking the trend of the curve is approximately $2.5 \mathrm{gr} / \mathrm{cc}$, which indicates that the lithology of the formation is mostly clay.

The third lane presents the compressional and shear wave velocities of the formation of interest, which has an average value of 12000 and $10000 \mathrm{ft} / \mathrm{sec}$ respectively.

16 $^{\text {th }}$ LACCEI International Multi-Conference for Engineering, Education, and Technology: "Innovation in Education and Inclusion", 19-21 July 2018, Lima, Peru. 


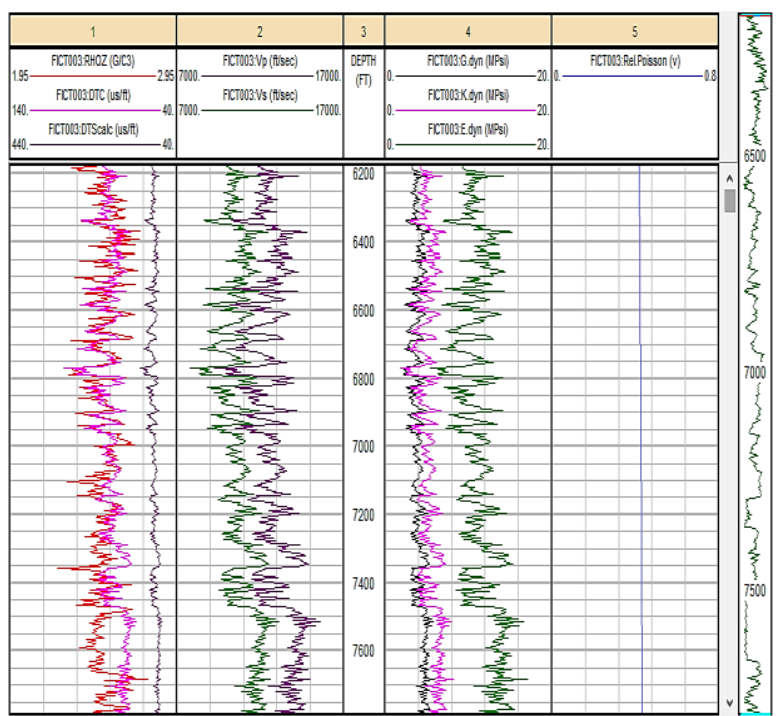

Fig. 5, Tiyuyacu Formation Elastic Properties 6178' - 7788' (Pozo FICT003)

Source: Herrera, et. al. 2017.

The depth of the well (lane 1), the tendency of the main stresses (lane 2), the resistance properties of the rock (lane 3) and the mud operational window (lane 4) of well FICT003 are shown in Figure 6.

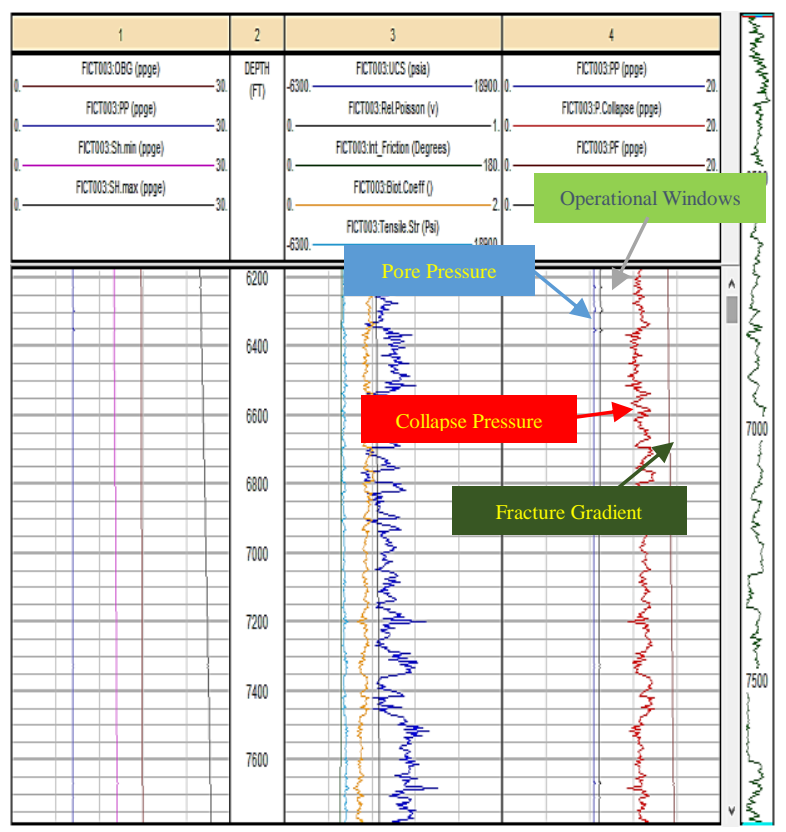

Fig.6, Tiyuyacu Formation Mud Operational Window 6178' - 7788' (Pozo FICT003)

Source: Herrera, et. al. 2017.

The third lane shows the properties of rock resistance, such as the uniaxial compressibility resistance, which has values of approximately 4000 - 7000 Psia. The tensile strength that is approximately $10 \%$ of the value of the UCS, which serves as an indicator so that the weight of the drilling mud does not exceed this value causing a tensile failure resulting in hydraulic fracturing

The Biot coefficient presents an average value of 0.80 , which is an indicator that the rock is an extremely plastic porous solid with a high pore pressure influence.

The suggested mud weight values for well FICT003 are shown in table 2.

Table 2. Suggested Mud Weight for Drilling the Tiyuyacu Formation in Well FICT003.

\begin{tabular}{|c|c|}
\hline \multicolumn{2}{|c|}{\begin{tabular}{c} 
uggested Mud Weight for Well FICT003 \\
\hline $\begin{array}{c}\text { Approx. Depth } \\
\text { [ft TVD] }\end{array}$
\end{tabular}} \\
\hline $6178-7425$ & $\begin{array}{c}\text { Mud Weight } \\
\text { [ppge] }\end{array}$ \\
\hline $7425-7788$ & $13.8-15.1$ \\
\hline
\end{tabular}

Source: Herrera, et. al. 2017.

Correlating the input data and the results obtained from the FICT001 and FICT003 wells for the TIYUYACU formation, we can establish a mud operational window sample guide for the entire ESPOL field, which is presented in Table 3:

Table 3. Suggested Mud Weight for Drilling the Tiyuyacu Formation in ESPOL field.

\begin{tabular}{|c|c|}
\hline \multicolumn{2}{|c|}{ Suggested Mud Weight for ESPOL field } \\
\hline $\begin{array}{c}\text { Approx. Depth } \\
\text { [ft TVD] }\end{array}$ & $\begin{array}{c}\text { Mud Weight } \\
\text { [ppge] }\end{array}$ \\
\hline TIYUYACU & $13.8-15.1$ \\
\hline TIYUYACU & $12.8-15.7$ \\
CONGLOMERATE & \\
\hline
\end{tabular}

Source: Herrera, et. al. 2017.

\section{CONCLUSIONS}

After analyzing the trend presented by the Sonic well log of the selected wells from the ESPOL field, it was observed that the formation of interest presents abnormal pressures due to the fact that the logs show a change in their slope. Those results in a variation of the pore pressure, this is due to the high level of clay that the formation contains, so it is concluded that in this field there are well mechanical problems in the drilling operations.

The magnitude of the vertical stress overload gradient was quantified with sufficient precision through the Zamora method which relates the geological age to the overload gradient, since the formation of interest belongs to a geological age between the Oligocene and the Eocene equation 2 was used. The OBG is in the order of $\sim 18.7$ ppge.

The magnitude of the pore pressure and fracture gradient was calculated with the Eaton method which correlates the gradients with the sonic well $\log$. With the analysis of geological studies carried out in the ESPOL field it was determined that the field contained a transcurrent fault, so the

16 $^{\text {th }}$ LACCEI International Multi-Conference for Engineering, Education, and Technology: "Innovation in Education and Inclusion", 19-21 July 2018, Lima, Peru. 
minimum and maximum horizontal stresses were calculated in a sliding regime, with equations 6 and 7, being in the order of $\approx 14.3 \mathrm{ppg}$ and $\approx 26.5 \mathrm{ppg}$ respectively.

The collapse pressure was calculated using the Mohr Coulomb fault criterion, considering the effective stress regime around the well.

By correlating the mud operational windows of the selected wells, a mud optimum window can be estimated for the TIYUYACU formation of the ESPOL field, which would be established in the range of 13.8-15.1 (ppge).

The geomechanical study will help optimize the drilling operations, avoiding mechanical problems of the well.

\section{RECOMMENDATIONS}

Before to making a Geomechanical design of this scope it is necessary to have a very good understanding of the regional and local geology of the area of interest.

To implement as a good practice, running density log, dipolar sonic (compressive and shear wave) log, image and caliper oriented logs, to minimize the uncertainties when we are making Geomechanical models.

In the case, if you are having core samples, firstly we should perform laboratory tests to determine the elastic and mechanical properties of rocks.

It is recommended, to acquire and use image logs in future wells to reduce uncertainties in determining the magnitude and orientation of horizontal stresses. The orientation of maximum horizontal stress is important in determining the best trajectory for drilling diverted wells.

Simulate the results to obtained elastic properties to set the elaboration of a 3D geomechanical model for the area, as well as updating the elastic properties of the rock as new wells are drilling in the area of interest.

For a better correlation data and to obtain a mud operational window with more precision for oilfield that is being studied, it is recommended to analyze two or more wells in future Geomechanical studies.

\section{ACKNOWLEDGMENT}

To Escuela Superior Politécnica del Litoral for opening its doors to us in its academic to do this research, and the Universidad Estatal peninsula de Santa Elena.

\section{REFERENCES}

[1] Barrera, J. (14 de Junio de 2012). Geology and Drilling Problems. Obtenido

https://geologyanddrillingproblems.wikispaces.com/INESTABILIDAD+ DEL+POZO.

[2] Barrios, J., Lobo, C., Oroño, M., \& Campos, A. (2017). Calibración de Mecánica de Rocas y Estabilidad de Hoyos en Yaciminetos Cretácicos Naturalmente Fracturados, Bloque XI, Cuenca de Maracaibo . SPE-WVS394, 17.

[3] Escuela Superior Politécnica del Litoral. (2004). Oil Well Drilling. Guayaquil: ESPOL.
[4] PETROAMAZONAS EP. (2017). Ronda Campos Menores.

[5] Benz, T., \& Nordal, S. (2000). Numerical Methods in Geothechnical Engineering. Boca Raton, FL: Taylor \& Francis Group.

[6] Gardner, G., Gardner, L., \& Gregory, A. (1974). Formation Velocity and Density - The Diagnostic Basics for Stratigraphic Traps. Geophysics. 39:770-780.

[7] Zamora, M. (1989). New Method Predicts Gradient Fracture . Houston: M-I Drilling Fluids Company.

[8] Eaton, B. A. (1975). The Equation for Geopressure Prediction from Well Logs. SPE 5544.

[9] Cavero, C. (2010). Análisis de Métodos para la Predicción de Presión de Poros Aplicado a la Estabilidad de Pozos de Perforación Petrolera.

[10] Breckels, I., \& Eekeln, H. (1982). Relationship Between Horizontal Stress and Depth in Sedimentary Basins. SPE 10336.

[11] Páramo, L. (2016). Análisis Geomecánico y de Estabilidad para el Pozo \#3 del Campo Caso Estudio. Universidad Nacional de Colombia.

[12] González, M. (2008). Análisis No Convencionales de Perfiles de Pozos y Estudio Geomecánico Aplicados al Área de Tomoporo. Zulia: Universidad de Zulia.

[13] Moos, D., Peska, P., \& Finkbeiner, T. (2003). Comprehensive Wellbore Stability Analysis Utilizing Quantitative Risk Assessment .

[14] Ewy, R. (1999). Wellbore Stability Predictions by Use of a Modified Lade Criterion. SPE 56862.

[15] Zoback, M. (2007). Reservoir Geomechanics. New York: Cambridge University.

16 $^{\text {th }}$ LACCEI International Multi-Conference for Engineering, Education, and Technology: "Innovation in Education and Inclusion", 19-21 July 2018, Lima, Peru. 